\title{
Quantitative Trait Loci in the Ogle/TAM O-301 Oat Mapping Population Controlling Resistance to Puccinia coronata in the Field
}

\author{
E. W. Jackson, D. E. Obert, J. B. Avant, S. A. Harrison, J. Chong, M. L. Carson, and J. M. Bonman
}

First, second, third, and seventh authors: United States Department of Agriculture-Agricultural Research Service (USDA-ARS), Small Grains and Potato Germplasm Research Unit, 1691 S. 2700 W., Aberdeen, ID 83210; fourth author: Louisiana State University (LSU), Wheat, Oat \& Coastal Plants Breeding, LSU School of Plant, Environmental and Soil Sciences, 104 Sturgis Hall, Baton Rouge $70803-$ 2110; fifth author: Agriculture and Agri-Food Canada, 195 Dafoe Rd., Winnipeg, Manitoba R3T 2M9, Canada; and sixth author: USDAARS, Cereal Disease Laboratory, 1551 Lindig Avenue, University of Minnesota, St. Paul 55108. Accepted for publication 24 December 2009.

\begin{abstract}
Jackson, E. W., Obert, D. E., Harrison, S. A., Chong, J., Avant, J. B., and Bonman, J. M. 2010. Quantitative trait loci in the Ogle/TAM O-301 oat mapping population controlling resistance to Puccinia coronata in the field. Phytopathology 100:484-492.

Crown rust is the most damaging disease of cultivated oat (Avena sativa) and genetic resistance is the primary means of controlling the disease. Quantitative trait loci (QTL) with major and minor effects have been identified in Ogle1040 and TAM O-301 (most notably, Pc58 and $P c N Q M G / L G C G$ from TAM O-301 and OT-27 from Ogle1040) through single-isolate greenhouse and field tests. To map loci and determine the effectiveness of previously identified QTL against naturally occurring pathogen populations in highly disease-conducive environments, the Ogle/TAM O-301 (OT) recombinant inbred line (RIL) population was grown in Texas and Louisiana over 2 years and in Manitoba, Canada. The

ticularly $P c 58 a$, accounted for most of the diseased leaf area (DLA) and infection type (IT) variance in all five experiments. Additionally, the genetic region characterized by $P c N Q M G / L G C G$ accounted for a portion of the IT variance in three experiments. Although no QTL was detected on OT-27 in this study, all the markers on this linkage group were associated $(P<0.0001)$ with reducing both IT and DLA using single-marker analysis. Screening with 25 Puccinia coronata isolates from six different states indicated that $P c 58 a b c$ and $P c 58 a$ were highly effective, while characterization using $\mathrm{F}_{2}$ populations derived from OT RILs containing the two main genetic regions responsible for crown rust resistance in TAM O-301 (Pc58 and PcNQMG/LGCG) and a minor QTL in Ogle (OT27) indicated that Pc58a, in combination with a locus in Ogle1040, provided high levels of resistance to natural races in Texas. This study provides new information and key loci in OT mapping population and may be useful for effective control of crown rust in North America.
\end{abstract} genetic region characterized by the Pc58 resistance gene complex, par-
Puccinia coronata, the casual organism of crown rust, is the most important disease of cultivated oat (Avena sativa L.) worldwide (30). To control this disease, several race-specific resistance loci from $A$. sativa and $A$. sterilis have been used in breeding programs across North America $(21,30)$. Because of the widespread use of race-specific loci and the resulting selection pressure, $P$. coronata has rapidly adapted and rendered most of the available loci either less effective or totally useless $(4,6,7,17-$ 20).

Several strategies, including gene pyramiding (24), the use of multilines (22), and partial resistance (24), have been proposed to improve durability of resistance to many diseases. Partial or racenonspecific resistance is appealing because it reduces the selection pressure placed on the pathogen. The major impediment to the use of partial resistance is the ability to transfer a complex trait. Marker-assisted selection could aid in the selection of partial resistance but geneticists must first accurately identify specific genetic regions associated with the resistance and develop useful markers. Few quantitative trait loci (QTL) for partial resistance to

Corresponding author: E. W. Jackson; E-mail address: Eric.Jackson@ars.usda.gov

* The $\boldsymbol{e}$-Xtra logo stands for "electronic extra" and indicates that the online version contains a table showing the genetic markers associated with reduced diseased leaf area and infection type phenotypes across five experiments.

doi:10.1094/PHYTO-100-5-0484

This article is in the public domain and not copyrightable. It may be freely reprinted with customary crediting of the source. The American Phytopathological Society, 2010. crown rust have been identified to date $(2,10,26)$, partly due to the lack of genetic markers and linkage maps available for oat $(1,27,32)$.

One of the most important mapping populations of cultivated oat was generated from the cross Ogle/TAM O-301 (OT) (27). The current OT map contains 441 genetic markers making up 34 linkage groups (LG). This population has been useful in identifying crown rust resistance loci and QTL in both Ogle and TAM O301. Although generally susceptible in North America, research has shown that Ogle1040 has two major loci and one minor QTL conferring resistance to specific $P$. coronata races $(3,14)$. TAM O301 also has crown rust resistance loci, most notably Pc58 and PcNQMG/LGCG $(12,15,30)$. Pc58 was recently shown to be a loosely-linked complex of three major loci designated Pc58a, $P c 58 b$, and Pc58c (12). Interestingly, the Pc58 complex has remained effective to common races of $P$. coronata in North America for many years $(4,6,8,17)$, and a completely susceptible reaction was not observed on OT lines containing Pc58a in our previous genetic mapping study (11).

Experiments using inoculum from a single race have shown that a "bleached fleck" phenotype consistently observed in the OT recombinant inbred lines (RILs) was conditioned by a major locus $P c N Q M G / L G C G$ in TAM O-301 (15). However, as with the individual locus in the Pc58 complex, the field effectiveness of this locus is unknown. The objectives of this study were to (i) identify via multiple location testing the loci or QTL in Ogle1040 and TAM O-301 conditioning resistance to common races of $P$. coronata in North America, (ii) determine the effectiveness of individual loci in the Pc58 complex, and (iii) study the genetic 
interaction of the major resistance loci in TAM O-301 and the minor QTL in Ogle1040.

\section{MATERIALS AND METHODS}

Field evaluations. The OT RIL population developed to construct the OT linkage map (27) was increased $\left(\mathrm{F}_{9}\right)$ for use in this study. The population was developed via single-seed descent to the $F_{6}$, where single panicle selections were made to produce $F_{7}$ lines. In the present study, $\mathrm{F}_{6: 9}$ seed derived from bulked $\mathrm{F}_{8}$ plants which each traced back to the original $F_{6}$ plants were used for field evaluations and mapping.

Experiments were conducted in 2005 and 2006. Parents and OT RILs were grown under natural disease pressure at the Louisiana State University AgCenter Ben Hur Farm in Baton Rouge, LA and on a grower's field in Castroville, TX through cooperation with the Texas A\&M AgriLife Research. Additionally, in 2006, parents and the population were grown at a third location at the Agriculture \& Agri-Food Canada field station, Glenlea, MB, Canada. Plots of parents and RILs were planted in mid-November for the Louisiana and Texas locations and early June for the Canadian location, all using a randomized complete block design with three replicates. Plots were first planted in two $2.44-\mathrm{m}$ rows with $0.36-\mathrm{m}$ spacing, and were then trimmed to $1.22 \mathrm{~m}$. Systematic plantings of a crown-rust-susceptible cultivar-Brooks (U.S. locations) or Makuru (Canadian location)—were included in all experiments to promote the spread of inoculum to test plots. Plots of each parent were randomly planted in each experiment. To study the $P$. coronata race structure in the Louisiana and Texas locations, 28 selected $P$. coronata differentials were planted in each block. In the Canadian location, 16 crown rust differentials were planted in each block.

Crown rust severity was quantitatively assessed in each experiment using diseased leaf area (DLA) and infection type (IT) ratings. For ratings at both 2005 locations in the United States and at the 2006 Canadian location, the entire plot within each replication/block/location was visually assessed and an overall mean rating was recorded. DLA was rated using the modified Cobb scale (25) as a reference, while ITs were scored on a 0-to-4 scale using the standard scoring system for wheat stem rust IT (28): $0=$ no or very faint hypersensitive flecks, ; = distinct hypersensitive flecks, 1 = small uredinia surrounded by distinct necrosis, $2=$ small uredinia surrounded by distinct chlorosis, $3=$ moderate sized with or without chlorosis, and $4=$ large uredinia without chlorosis or necrosis. In the two 2006 U.S. locations, three flag leaves best representing overall disease for each plot were harvested and images were taken from a fixed distance of $27.9 \mathrm{~cm}$ using an Olympus C7070 digital camera (3,072 by 2,304 pixels). DLA and ITs were then recorded for each plot from capture images using the previously described methods (28).

Quantitative mapping. Crown rust DLA and IT means (11) and variances were calculated for genotype, replicates within each experiment, experiment, and genotype $\times$ experiment using the JMP 6.0.2 statistical software (SAS Institute, Cary, NC). DLA and IT means from each experiment were treated as separate traits in this study due to an overall significant genotype $x$ experiment interaction $(P<0.0001$; analysis of variance [ANOVA] $)$. Because each experiment was treated as a separate trait, broad-sense heritabilities were calculated per experiment using the genotypic variance divided by the combined genotype + replicate + genotype $\times$ replicate + error variances, as previously modified (15) to include the replication variance from the method described by Zhu and Kaeppler (36), where $\mathrm{h} 2=\sigma_{\mathrm{g}}^{2} /\left(\sigma_{\mathrm{g}}^{2}=\sigma_{\mathrm{r}}^{2}=\sigma_{\mathrm{g} \times \mathrm{r}}^{2}=\sigma_{\mathrm{e}}^{2}\right)$.

Variability in DLA and IT among the OT RILs in each experiment were quantitatively mapped using WinQTL Cartographer (31). Genotype and phenotype mapping analysis was done using the adjusted OT linkage map defined by Jackson et al. (14) with the addition of mapped crown rust resistance phenotypic markers $(12,14)$. To determine specific areas of the Ogle and TAM O-301 genome associated with reducing crown rust infection, single-marker analysis (SMA) was performed. Subsequently, QTL were detected for each trait by experiment using composite interval mapping (CIM) (31). Co-factors for CIM were selected using forward regression with a significance threshold of $P=$ 0.05. Significant QTL were determined using experiment-wise significance levels established by running 1,000 permutations for all traits, $\alpha=0.05$ (9). QTL intervals were assigned based on the area within one likelihood of the odds (LOD) score of the QTL peak. QTL were considered valid in the study if they were detected in more than one environment. To estimate the total phenotypic variance explained by the valid QTL, multiple interval mapping (MIM) was performed using marker and linkage group positions of QTL identified with CIM.

Effects of qualitative loci and characterization. The effectiveness of different Pc58 loci was assessed in all U.S. experiments by subdividing the OT RILs into "Pc58-classes" based on the locus or combination of loci in each RIL as defined previously (12). DLA and IT means and variances were calculated for Pc58class, replicates within each experiment, experiment, and Pc58class $\times$ experiment using the JMP 6.0.2 statistical software (SAS Institute). Because a significant Pc58-class $\times$ experiment interaction $(P<0.0001$; ANOVA) was observed between Texas and Louisiana experiments, but not between experiments at each location $(P=0.05)$, data for each crown rust assessment collected in both years were combined from each location for analysis and, significant differences were determined between means using Tukey Kramer's highly significant difference (HSD).

The effectiveness of the different Pc58 loci was tested using a broad spectrum of $P$. coronata races. Fifteen selected OT RILs representing five of the seven Pc58-classes (Pc58abc, a, b, ac, and no Pc58) along with the parental lines (TAM-O-301 and Ogle); a universally susceptible check cultivar, Marvelous; and MN841801, a line with loci for complete and partial resistance (adult plant resistance) to crown rust were inoculated separately with 25 single-urediniospore isolates of $P$. coronata from the 2007 U.S. crown rust survey. Isolates were selected based on the diversity of their reactions on TAM-O-301, which is used as a crown rust differential in the race survey. Single-uredinial derived cultures of the isolates were stored at $-50^{\circ} \mathrm{C}$ and inoculum was increased on seedlings of either Marvelous or Starter. The test lines were grown in vermiculite in $7-\mathrm{cm}^{2}$ pots with 10 to 20 seeds of each of four different lines planted in each corner of the pot. Seven days after planting, primary leaves of seedlings in each set of lines was inoculated by spraying with fresh urediniospores suspended in light mineral oil (Soltrol 70; ConocoPhillips Inc., Houston, TX). The mineral oil was allowed to evaporate for $\approx 30 \mathrm{~min}$ and the plants were placed in a dew chamber at $18^{\circ} \mathrm{C}$ overnight, then moved to a greenhouse for disease development. Crown rust reactions were measured 10 to 12 days after inoculation using the previously described 0 -to-4 scale (28).

To further study key alleles reducing crown rust severity in both Ogle1040 and TAM O-301, crosses were made between the susceptible crown rust cv. Provena and four OT RILs (OT-14, -38, -62 , and -112) putatively containing the major crown rust resistance loci, designated Pc58a, Pc58b, Pc58c (12), and PcNQMG/ $L G C G$ (15), and a minor QTL from Ogle1040 located on OT-27 (14). Two $F_{1}$ seed resulting from each cross were sown in $15.24-\mathrm{cm}$ pots in the greenhouse. Plants were grown to maturity and $\approx 100$ seeds were harvested from each $\mathrm{F}_{1}$ plant. In all, $150 \mathrm{~F}_{2}$ seeds from each cross were planted in the 06-Castroville experiment. Each $\mathrm{F}_{2}$ population was planted in a continuous row, with 12 seeds of the corresponding parents planted at the beginning and end of each row.

Eight plants of each parent and all $\mathrm{F}_{2}$ plants were rated for IT. The pathogen produced moderate-size uredinia without chlorosis on the Ogle1040 parent and small uredinia surrounded by distinct 
chlorosis on the TAM O-301 parent. The $\mathrm{F}_{2}$ progeny from each population were initially grouped into two phenotypic classes. $F_{2}$ progeny displaying moderate to large uredinia were classified as susceptible (S), whereas progeny displaying small uredinia surround by both relatively large and relatively small chlorotic zones were classified as highly resistant (R) (Fig. 1). The resulting segregation ratios of R:S progeny were compared with the common Mendelian ratios using $\chi^{2}$ analysis. In addition, $\mathrm{F}_{2}$ progeny were further subdivided into an intermediate phenotypic subclass (I) based on pustule size within the chlorotic fleck (Fig. 1) and the resulting R:I:S data was compared with known Mendelian ratios to determine possible gene action.

\section{RESULTS}

Field experiments. Conditions for crown rust disease development were adequate for disease phenotyping in all five experiments. The 05-Castroville experiment had the highest disease severity across all entries (43.2\% DLA, $P>0.05$ HSD) and the 06-Baton Rouge experiment (11.2\% DLA) and the 06-Glenlea
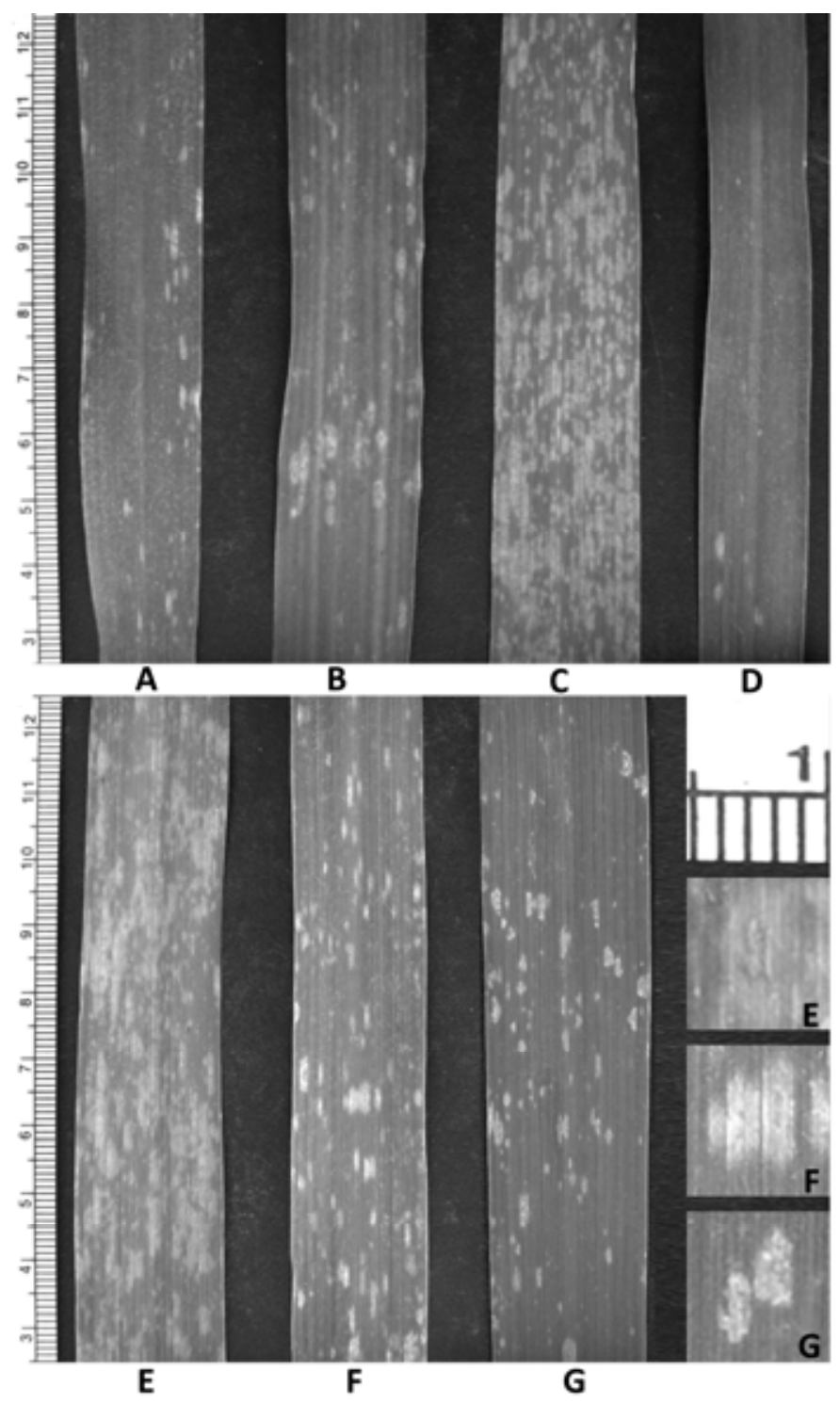

Fig. 1. Disease reactions of parents and $F_{2}$ progeny to naturally occurring Puccinia coronata population in Castroville, TX. Genotypes are A, the Ogle/TAM O-301 recombinant inbred line OT-38; B, Provena; C, Ogle; D, TAM O-301; and E, susceptible; $\mathbf{F}$, resistant; and $\mathbf{G}$, intermediate OT38/Provena $\mathrm{F}_{2}$ progeny. Magnified E, susceptible; F, resistant and $\mathbf{G}$, moderately resistant infection types are shown on the lower right. experiment (11.1\% DLA) had the lowest disease severities (Table 1). Crown rust development in each location was uniform except in the 06-Castroville experiment, where the second replicate had higher $(P>0.05$ HSD) DLA $(23.8 \%)$ than replicates one $(16.0 \%)$ and three $(13.8 \%)$. IT ratings did not differ between replications ( $P=0.1047$, ANOVA), while the overall highest mean IT was observed in 06-Castroville experiment followed by 06-Glenlea, 06-Baton Rouge, 05-Baton Rouge, and 05-Castroville (Table 1).

Quantitative mapping. TAM O-301 had lower $(P>0.05)$ mean DLA than Ogle1040 in all experiments except 06-Castroville (Table 1). In all experiments except 06 -Catroville, IT ratings of moderate to large uredinia without chlorosis or necrosis were observed on Ogle1040 and hypersensitive flecks to flecks with small uredinia were observed on TAM O-301 (Table 1; Fig. 2). In the 06-Castroville test, DLA did not differ between the parental lines; however, Olge1040 had large uredinia without chlorosis compared with small uredinia surrounded by distinct chlorosis observed on TAM O-301 (Fig. 2). Across all experiments, considerable variability in DLA and IT was observed between the OT RILs. Broad-sense heritability estimates indicated that 55.4 to $82.8 \%$ of the reduced DLA was due to genetic components in all experiments except in the 05-Castroville environment, whereas genetic components accounted for 41.8 to $88.1 \%$ of the reduction in ITs across all experiments (Table 1).

SMA identified genetic markers on six OT linkage groups associated $(P>0.05)$ with reducing DLA and IT. Subsequent analysis using CIM detected QTL reducing both traits associated with the same genetic markers on three of the OT linkage groups. Of the genetic markers only identified in SMA, three markers on OT- 2 and OT- 8 and all the markers making up OT-27 were associated with reducing DLA and IT in at least one experiment (online $e$-Xtra).

CIM analysis detected three QTL, one each on OT-11, OT-15, and OT-32, in reducing crown rust IT (Table 2). Of these, only the QTL on OT-32 was detected in all five experiments. The QTL interval mapped to a 6.4-centimorgan $(\mathrm{cM})$ region characterized by restriction fragment length polymorphism (RFLP) markers PSR637, PSR160, and CDO545b (Table 2; Fig. 3). The peak (LOD 8.4 to 16.4) mapped $\approx 0.51 \mathrm{cM}$ from the crown rust resistance locus Pc58 $a$ and was associated with TAM O-301 alleles explaining an average of $21.68 \%$ of the IT variation across the five experiments. The same QTL interval also reduced DLA in all five experiments (Table 3; Fig. 3). The peak (LOD 2.9 to 18.3) as detected by DLA mapped $0.29 \mathrm{cM}$ from Pc58a and accounted for an average of $22.04 \%$ of the phenotypic variation across all experiments.

The QTL-reducing IT on OT-11 was detected in the 05Castroville and the 06-Glenlea experiments (Table 2). The QTL interval mapped to a 13.6-cM region characterized by RFLP markers RZ574b, BDC1823a, and amplified fragment length polymorphism (AFLP) marker e50-m61-148.t (Fig. 3). The peak (LOD 11.4 to 14.7 ) mapped $\approx 6.7 \mathrm{cM}$ from the crown rust resistance locus PcNQMG/LCGC and was associated with TAM O301 alleles accounting for an average of $34.55 \%$ of the IT variation across both experiments. The same QTL interval on OT11 was detected using DLA in the 05-Castroville experiment (Table 3; Fig. 3). The peak (LOD 6.5) mapped $10.7 \mathrm{cM}$ from the crown rust resistance locus $P c N Q M G / L C G C$ and accounted for $13.4 \%$ of the DLA variation. One additional QTL-reducing IT was also detected on OT-11 in the 06-Baton Rouge experiment. However, it will need to be validated with further testing to be considered valid because it only occurred in one environment (Table 2; Fig. 3).

The QTL on OT-15 was detected in the 06-Castroville experiment reducing IT (Table 2) and in the 06-Baton Rouge experiment reducing DLA (Table 3). The QTL interval mapped to a 30.6-cM region characterized by RFLP probes UMN97c and ISU 47b for IT and a 9.9-cM region characterized by RFLP probe CDO412 for DLA (Tables 2 and 3; Fig. 3). The QTL accounted 
for $4.7 \%$ of the IT variation and $8.0 \%$ of the DLA variation in the respective experiment.

MIM analysis indicated the combined QTL within each location accounted for 25.6 to $76.3 \%$ of the total IT variation (Table
2). In contrast, for DLA, more than one QTL was only detected in the 05-Castroville and 06-Baton Rouge experiments. In these experiments, MIM analysis indicated that the combined QTL accounted for $56.1 \%$ of the total DLA in the 05-Castroville

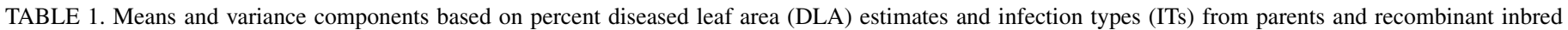
lines (RILs) grown under natural disease pressure in multiple locations and years

\begin{tabular}{|c|c|c|c|c|c|c|c|}
\hline \multirow[b]{2}{*}{ Trait, year-environment } & \multicolumn{3}{|c|}{$\operatorname{Mean}^{\mathrm{x}}$} & \multirow[b]{2}{*}{ Location mean ${ }^{y}$} & \multicolumn{3}{|c|}{ Variance components ${ }^{\mathrm{z}}$} \\
\hline & Ogle & TAM O-301 & RILs & & $\sigma_{G}^{2}$ & $\Sigma_{\mathrm{G} \times \mathrm{E}}^{2}$ & Heritability \\
\hline \multicolumn{8}{|l|}{ DLA } \\
\hline 05-Castroville, TX & $81.1 \mathrm{a}$ & $29.2 \mathrm{c}$ & $41.3 \mathrm{~b}$ & $43.2 \mathrm{~A}$ & 222.2 & 104.9 & 5.5 \\
\hline 05-Baton Rouge, LA & $29.7 \mathrm{a}$ & $2.5 \mathrm{~b}$ & $16.7 \mathrm{~b}$ & $17.3 \mathrm{~B}$ & 630.0 & 115.4 & 55.4 \\
\hline 06-Castroville, TX & 16.5 & 18.4 & 17.9 & $17.9 \mathrm{~B}$ & $1,937.2$ & 148.9 & 82.8 \\
\hline 06-Baton Rouge, LA & $10.2 \mathrm{a}$ & $2.9 \mathrm{~b}$ & $11.7 \mathrm{a}$ & $11.2 \mathrm{C}$ & 192.5 & 90.8 & 65.7 \\
\hline 06-Glenlea, MB, Canada & $53.8 \mathrm{a}$ & $0.1 \mathrm{~b}$ & $10.2 \mathrm{~b}$ & $11.1 \mathrm{C}$ & 754.7 & 50.9 & 57.0 \\
\hline \multicolumn{8}{|l|}{ IT } \\
\hline 05-Castroville, TX & $2.5 \mathrm{a}$ & $0.1 \mathrm{c}$ & $0.7 \mathrm{~b}$ & $0.8 \mathrm{E}$ & 1.2 & 0.6 & 63.2 \\
\hline 05-Baton Rouge, LA & $2.8 \mathrm{a}$ & $0.4 \mathrm{c}$ & $1.3 \mathrm{~b}$ & $1.3 \mathrm{D}$ & 4.0 & 0.5 & 88.1 \\
\hline 06-Castroville, TX & 3.8 & 2.8 & 3.2 & $3.2 \mathrm{~A}$ & 3.5 & 0.2 & 85.4 \\
\hline 06-Baton Rouge, LA & $3.9 \mathrm{a}$ & $1.1 \mathrm{c}$ & $2.2 \mathrm{~b}$ & $2.2 \mathrm{C}$ & 2.9 & 0.8 & 45.3 \\
\hline 06-Glenlea, MB, Canada & $3.0 \mathrm{a}$ & $1.6 \mathrm{~b}$ & $2.5 \mathrm{a}$ & $2.5 \mathrm{~B}$ & 2.3 & 0.6 & 41.8 \\
\hline
\end{tabular}

${ }^{\mathrm{x}}$ Mean percent DLA and IT for each RIL was based on estimates from flag leaves of 9 plants, whereas percent DLA for each parent was based on 35 plants. DLA was estimated using the modified Cobb scale as a reference. Means within each year and environment (row) followed by the same lowercase letter are not significantly different (highly significant difference [HSD], $P=0.05$ ).

${ }^{\mathrm{y}}$ Year-environment location mean across all entries for DLA or IT (column) followed by the same uppercase letter is not significantly different (HSD, $\left.P=0.05\right)$.

${ }^{\mathrm{z}}$ Components: $\sigma^{2}=$ interaction variances, $\mathrm{G}=$ genotype, $\mathrm{E}=$ replications.
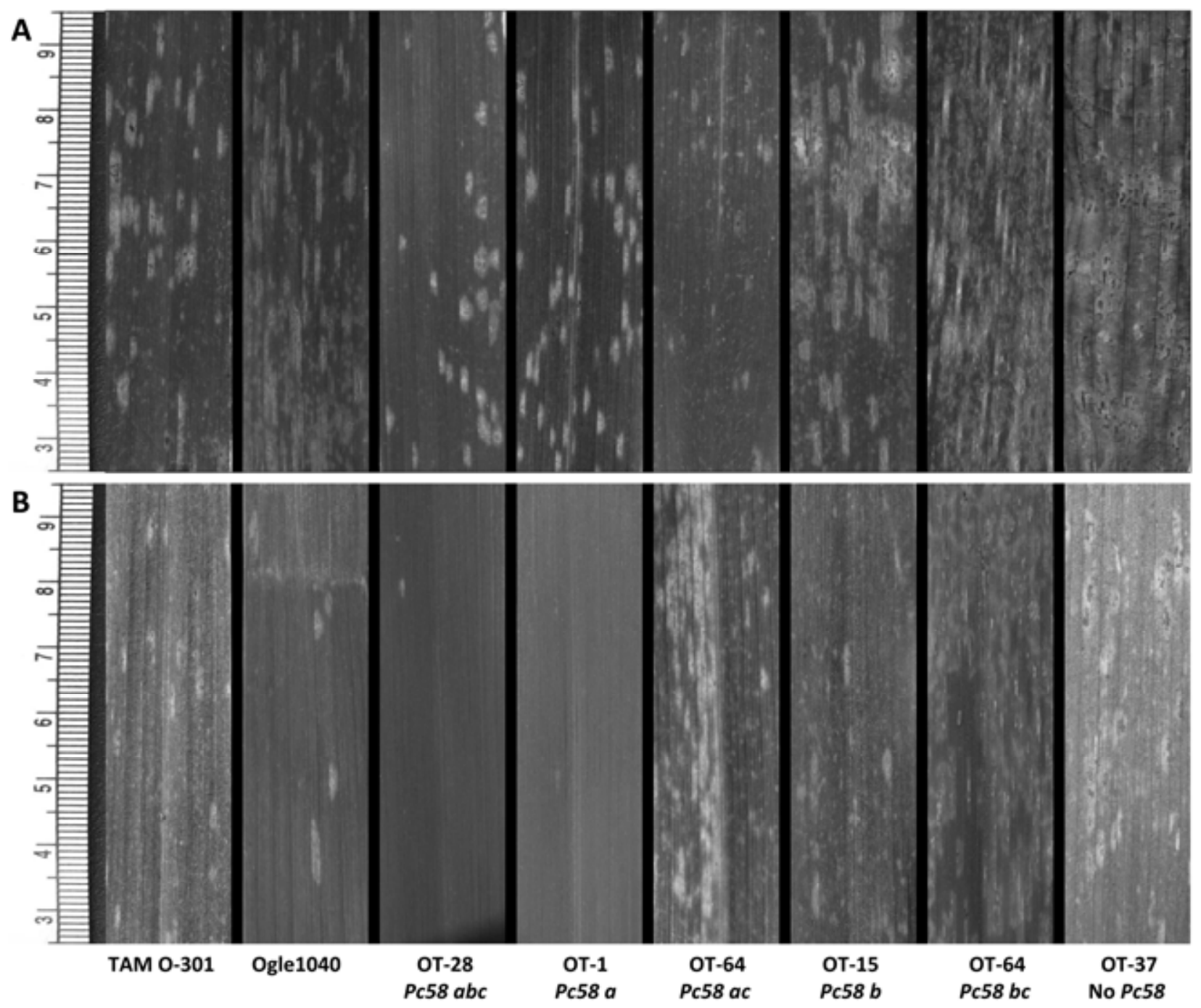

Fig. 2. Disease reactions of oat genotypes to naturally occurring Puccinia coronata population in A, Castroville, TX and B, Baton Rouge, LA in 2006. Genotypes consist of Ogle, TAM O-301, and Ogle/TAM O-301 (OT) recombinant inbred lines with different $P c 58$ loci. 
experiment and $13.6 \%$ of the total DLA variation in the 06-Baton Rouge experiment (Table 3 ).

Effects of qualitative loci and characterization. Analysis of the seven different Pc58 classes showed that only OT RILs with
$P c 58 a, P c 58 a b, P c 58 a c$, and $P c 58 a b c$ had reduced DLA $(P>$ 0.05 HSD) compared with RILs containing no Pc58 loci in the U.S. experiments (Table 4). Similarly, the same Pc58 classes also reduced IT $(P>0.05, \mathrm{HSD})$ in the United States (Table 4).

TABLE 2. Quantitative trait loci (QTL) analysis summary for crown rust resistance based on infection type (IT) estimated on leaves of Ogle/TAM O-301 $\mathrm{F}_{6: 9}$ recombinant inbred lines (RILs) grown under natural crown rust disease pressure in multiple locations and years

\begin{tabular}{|c|c|c|c|c|c|}
\hline$\underline{\text { Year-environment }}$ & Linkage group & QTL marker (peak/interval) ${ }^{\mathrm{w}}$ & LOD $^{x}$ & $R^{2}(\%)^{\mathrm{y}}$ & Additive effect \\
\hline \multirow[t]{2}{*}{ 05-Castroville, TX } & OT-11 & BCD1823a (19.7/14.4-25.0) & 11.4 & 25.1 & 0.5 \\
\hline & OT-32 & PSR637 (0.01/0.0-1.2) & 15.7 & 30.2 & 0.5 \\
\hline Total $^{\mathrm{z}}$ & & & & 59.0 & \\
\hline \multirow[t]{2}{*}{ 06-Castroville, TX } & OT-15 & UMN97c (55.9/52.5-83.1) & 2.7 & 4.7 & 0.1 \\
\hline & OT-32 & PSR637 (0.01/0.0-1.7) & 16.4 & 37.2 & 0.4 \\
\hline Total $^{\mathrm{z}}$ & & $\ldots$ & $\ldots$ & 44.0 & $\ldots$ \\
\hline 06-Baton Rouge, LA & OT-11 & BCD828a (95.1/93.7-98.7) & 3.7 & 7.4 & 0.2 \\
\hline \multirow{2}{*}{ 06-Glenlea, MB, Canada } & OT-11 & BCD1823a (15.7/11.4-19.9) & 14.7 & 44.0 & 0.6 \\
\hline & OT-32 & PSR637 (2.0/0.6-6.4) & 11.5 & 22.4 & 0.4 \\
\hline Total $^{\mathrm{z}}$ & $\ldots$ & $\ldots$ & $\ldots$ & 76.3 & $\ldots$ \\
\hline
\end{tabular}

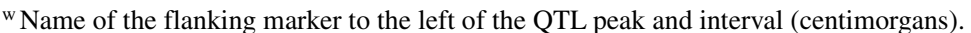

${ }^{x}$ QTL were detected using WinQTL Cartographer composite interval mapping and were based on a LOD threshold of 2.6 (1,000 permutations and a type I error of 5\%).

y Percentage of the phenotypic variation explained by the QTL.

${ }^{\mathrm{z}}$ Portion of the total variance explained by the QTL using multiple interval mapping.

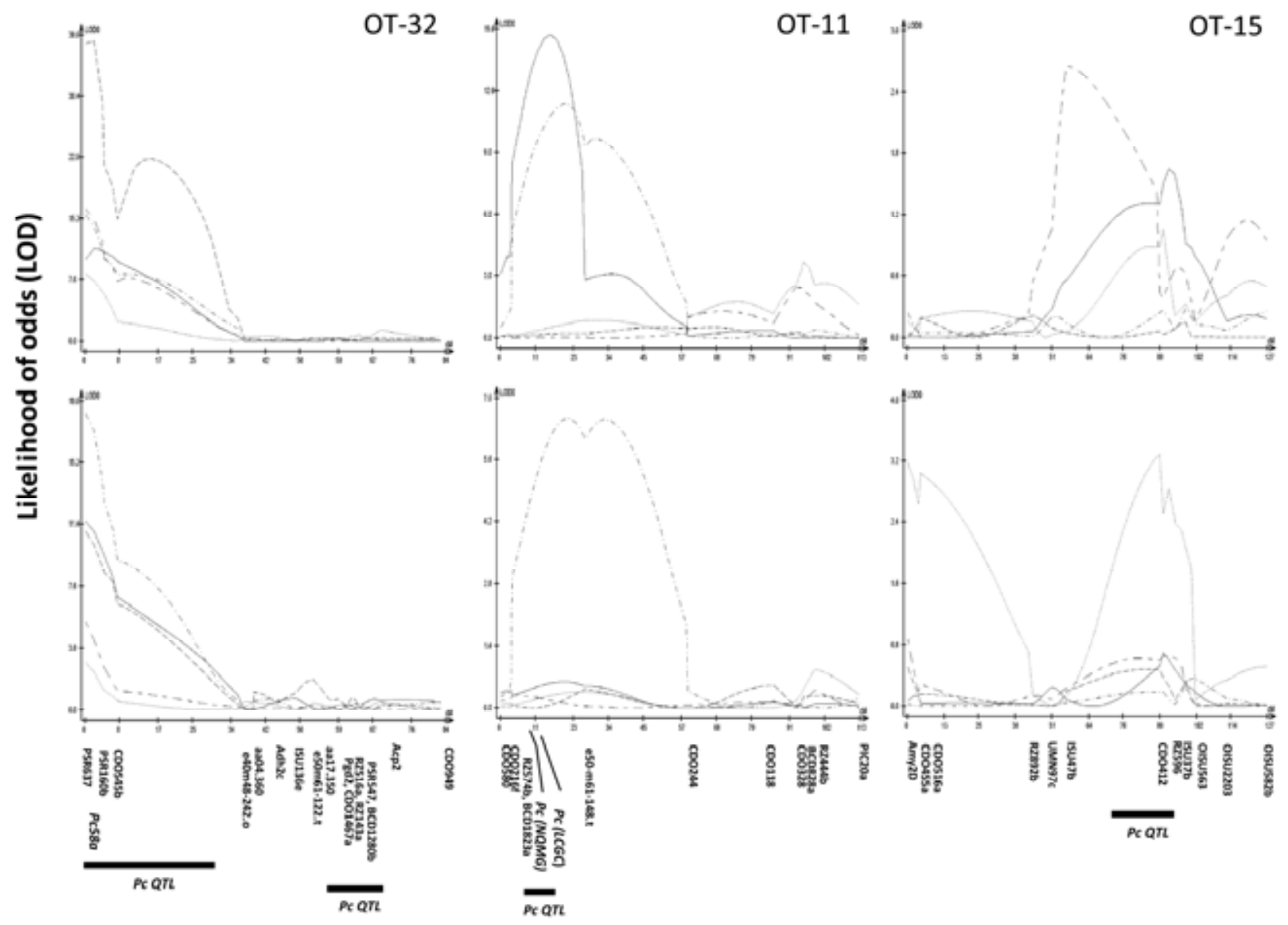

Linkage group position (cM)

Fig. 3. Quantitative trait loci (QTL) on the Ogle/TAM O-301 (OT) linkage groups (32, 11, and 15) based on infection type (IT, top) and diseased leaf area (DLA, bottom). QTL were detected using WinQTL Cartographer CIM with a significant log of the likelihood ratio (LOD) (y-axis) thresholds of 2.6 and 2.7 for IT and DLA, respectively (1,000 permutations and a type I error of 5\%). Traits were based on IT and DLA measured on the 136 OT recombinant inbred lines rated in Castroville, TX 2005 (-•), Baton Rouge, LA 2005 (--), Baton Rouge, LA 2006 (••), Castroville, TX 2006 (---), and Glenlea, MB, Canada 2006 (solid line). Genetic markers (x-axis) including restriction fragment length polymorphism probes (BCD, CDO, PSR, ISU, RZ, and UMN) and amplified fragment length polymorphism (e and aa), intron (Amy), isozyme (Acp, Adh, and Pgd), and sorghum resistance gene analog (PIC) markers were mapped using Mapmaker 3.0/EXP with an LOD threshold of 3.0. In addition, phenotypic markers for crown rust resistance loci $P c$ and QTL intervals from previous reports $(14,15)$ were also placed on the charts. 
Virulence tests using 25 pathogenically distinct $P$. coronata isolates on Ogle1040, TAM O-301, and selected OT RILs with different resistance loci combinations of the Pc58 complex produced consistent results. None of the isolates produced a fully susceptible reaction, defined by an IT of 4 on TAM O-301, whereas 20 produced an IT of 4 on Ogle1040 seedlings (Table 5). In addition, TAM O-301 was resistant to 15 of the isolates. OT RILs containing no Pc58 locus were also susceptible to 20 to 24 of the 25 isolates and no resistant reactions were observed to remaining races (Table 5). In contrast, only three to four of the isolates were completely virulent on OT RILs containing Pc58abc, whereas several resistant reactions were observed to the remaining races. Comparing the OT RILs with Pc58a to those with $P c 58 b$, fewer isolates (two to seven) were completely virulent on RILs with $P c 58 a$, whereas more avirulent reactions were observed on RILs with Pc58b (Table 5).

In the 06-Castroville field experiment, the parental line TAM O-301 was moderately resistant $(\mathrm{IT}=2)$ whereas the parental line Ogle 1040 was susceptible (IT = 3 to 4 ). In addition, data from the OT RILs planted in the same environment showed that OT lines containing only PcNQMG/LCGC were moderately susceptible whereas lines containing only Pc58 loci were moderately resistant. This was displayed in the previous result, where no QTL were detected using the IT data from the 06-Castroville experiment (Table 2). Segregation of susceptible and moderately resistant to highly resistant reactions (Fig. 1) in the $\mathrm{F}_{2}$ progeny from all four populations was not different $(P=0.05)$ from a $3 \mathrm{R}: 1 \mathrm{~S}$ Mendelian model for a single dominant locus (Table 6). In addition, segregation of susceptible, moderately resistant, and highly resistant reactions (Fig. 4) of all four populations was not different $(P=0.05)$ from a 9R:3MR:4S model for a two-dominant-gene additive model (Table 6; Fig. 4). Combined results from all four populations were a satisfactory fit to both models (Table 6). All populations were homogeneous, suggesting that the same loci were responsible for resistance from all four OT RILs (Table 6).

\section{DISCUSSION}

Uniform crown rust infection can be difficult to achieve in field environments, especially when conditions are not conducive in a particular year. However, in spite of such difficulties, generating disease data for populations designed to map resistant loci in environments where the crop will be grown is essential to evaluate the practical utility of the loci identified. In the present study, we used three rust-prone production areas in North America where severe crown rust epidemics often occur. During 2005 and 2006, large variations in crown rust severities were found across the different locations. These differences most likely were a result of environmental conditions, including $P$. coronata race structure, and inoculum level. Differences in race structure between the two U.S. locations were evident from the reactions of the crown rust differentials. In the 05- and 06-Baton Rouge experiments, 6 (Pc14, 35, 36, 38, 39, and 40) of the 28 differentials were susceptible to the races, with the only difference over the 2 years being a fully susceptible reaction on Pc38 in 2006. Races in the Castroville location apparently were more complex than those in the Baton Rouge location because, in the 05Castroville test, 8 (Pc14, 35, 36, 38, 40, 60, 61, 64, and 71) of the 28 differentials were susceptible (20) and, in the 06-Castroville test, 14 (Pc 14, 35, 36, 39, 40, 46, 48, 51,54, 56, 60, 61, 62, and $71)$ were susceptible. This is in agreement with a previous report (18), where races from northern Mexico and Texas were more complex than those from central Mexico and the Yucatan Peninsula. With the Canadian prairie location, unfortunately, only 14 of the 28 differentials were tested in 2006 and, of these 14, 5 (Pc38, $39,40,56$, and 68) were susceptible. The susceptibility of the Pc68 differential in the Canadian location due to rapid increase in virulence to this locus in recent years has made this population distinct from other populations in the United States (4).

TABLE 4. Mean percent diseased leaf area (DLA) of parents and $\mathrm{F}_{6: 9}$ Ogle $\times$ TAM O-301 recombinant inbred lines containing different Pc58 gene combinations grown under natural disease pressure in Louisiana and Texas over 2 years

\begin{tabular}{lcc}
\hline Location, candidate $P c$ gene & No. of lines ${ }^{\mathrm{y}}$ & DLA $(\%)^{\mathrm{z}}$ \\
\hline Baton Rouge, LA & & \\
Ogle (No $P c$ loci) & 35 & $28.5 \mathrm{~A}$ \\
$P c 58 b$ & 16 & $27.5 \mathrm{~A}$ \\
No $P c$ loci & 36 & $26.3 \mathrm{~A}$ \\
$P c 58 b$ and $c$ & 7 & $24.1 \mathrm{~A}$ \\
TAM O-301 $(P c 58 a, b$, and $c)$ & 35 & $12.7 \mathrm{~B}$ \\
$P c 58 a$ and $b$ & 4 & $10.5 \mathrm{~B}$ \\
$P c 58 a$ and $c$ & 18 & $10.5 \mathrm{~B}$ \\
$P c 58 a, b$, and $c$ & 35 & $9.5 \mathrm{~B}$ \\
$P c 58 a$ & 14 & $9.4 \mathrm{~B}$ \\
HSD $(P=0.05)$ & $\ldots$ & 6.3 \\
Castroville, TX & 35 & \\
Ogle (No $P c$ loci) & 16 & $81.0 \mathrm{~A}$ \\
$P c 58 b$ & 36 & $63.1 \mathrm{~B}$ \\
No $P c$ loci & 7 & $59.2 \mathrm{~B}$ \\
$P c 58 b$ and $c$ & 35 & $54.3 \mathrm{~B}$ \\
TAM O-301 $(P c 58 a, b$, and $c)$ & 4 & $28.8 \mathrm{D}$ \\
$P c 58 a$ and $b$ & 18 & $35.0 \mathrm{D}$ \\
$P c 58 a$ and $c$ & 35 & $27.2 \mathrm{D}$ \\
$P c 58 a, b$, and $c$ & 14 & $29.1 \mathrm{D}$ \\
$P c 58 a$ & $\ldots$ & $23.9 \mathrm{D}$ \\
HSD $(P=0.05)$ & 9.1 \\
\hline
\end{tabular}

${ }^{\mathrm{y}}$ Lines containing no $P c 58$ loci or varying combinations of the three different loci of the Pc58 complex were based on data from Hoffman et al. (12).

${ }^{\mathrm{z}}$ Mean DLA followed by the same letter within a location were not significantly different $(P=0.05$, Tukey-Kramer highly significant difference [HSD]).

TABLE 3. Quantitative trait loci (QTL) analysis summary for crown rust resistance based on percent disease leaf area (DLA) estimated on leaves of Ogle/TAM O$301 \mathrm{~F}_{6: 9}$ recombinant inbred lines (RIL) grown under natural crown rust disease pressure in multiple locations and years

\begin{tabular}{|c|c|c|c|c|c|}
\hline Year-environment & Linkage group & QTL marker (peak/interval) $^{\mathrm{w}}$ & $\operatorname{LOD}^{\mathrm{x}}$ & $R^{2}(\%)^{\mathrm{y}}$ & Additive effect \\
\hline \multirow[t]{2}{*}{ 05-Castroville, TX } & OT-11 & BCD1823a (21.7/12.6-43.9) & 6.5 & 13.4 & 8.4 \\
\hline & OT-32 & PSR637 (0.01/0.0-1.8) & 18.3 & 35.6 & 13.9 \\
\hline Total $^{\mathrm{z}}$ & & & & 56.1 & \\
\hline 06-Castroville, TX & OT-32 & PSR637 (0.01/0.0-1.7) & 5.5 & 14.7 & 3.4 \\
\hline \multirow[t]{2}{*}{ 06-Baton Rouge, LA } & OT-15 & CDO412 (88.83/80.1-90.0) & 3.3 & 8.0 & 2.2 \\
\hline & OT-32 & PSR637 (0.01/0.0-2.8) & 2.9 & 7.2 & 2.1 \\
\hline Total $^{z}$ & & $\ldots$ & $\ldots$ & 13.6 & $\ldots$ \\
\hline
\end{tabular}

${ }^{w}$ Name of the flanking marker to the left of the QTL peak and interval (centimorgans).

${ }^{x}$ QTL were detected using WinQTL Cartographer composite interval mapping and were based on a log of the likelihood ratio (LOD) threshold of 2.7 (1,000 permutations and a type I error of 5\%).

y Percent of the phenotypic variation explained by the QTL.

${ }^{\mathrm{z}}$ Portion of the total variance explained by the QTL using multiple interval mapping. 
Ogle had higher DLA and IT ( $P>0.05$, HSD) than TAM O-301 in all five experiments with the exception of 06-Castroville, in which Ogle also had numerically higher DLA and IT than TAMO-301; however, this difference was not significant. This result could be due to a change in the overall race structure in the population between 2005 and 2006, as evidenced by an increase in the number of differentials being susceptible to the rust from 2005 to 2006. The additional isolates present in 2006 might have the specific virulence for a particular resistance locus or loci in TAM O-301, resulting in increased virulence expressed as larger uredinia on TAM-O-301.

In the present multilocation study, SMA revealed association of the isozyme marker for shikimate dehydrogenase ( $\mathrm{Skdh}$ ) on OT-2 with reduced DLA in the 05-Baton Rouge experiment and with reduced IT in the 05-Castroville and Baton Rouge experiments (online $e$-Xtra). In addition, two RFLP probes, BCD1235d and Bcd1087, linked to Skdh were associated with reduced DLA in the 06-Glenlea test. This result supports previous findings (14), where a QTL associated with Skdh on OT-2 was detected using a newly developed quantitative polymerase chain reaction assay to precisely measure fungal DNA in single-isolate experiments in the field and greenhouse. Furthermore, previous studies have linked Skdh to resistance loci in various pathosystems, including

TABLE 5. Reactions of Ogle, TAM O-301, and Ogle/TAM O-301 (OT) recombinant inbred lines selected based on Pc58 gene differences to 25 different Puccinia. coronata isolates collected in six different states

\begin{tabular}{lllrrrr}
\hline & & \multicolumn{5}{c}{ ITs and no. of isolates ${ }^{\mathrm{z}}$} \\
\cline { 3 - 7 } Genotype & $P c 58^{\mathrm{y}}$ & 0 & 1 & 2 & 3 & 4 \\
\hline Ogle & None & 0 & 0 & 0 & 5 & 20 \\
TAM O-301 & $a b c$ & 0 & 12 & 3 & 10 & 0 \\
OT-14 & $a b c$ & 1 & 4 & 4 & 12 & 4 \\
OT-62 & $a b c$ & 0 & 6 & 2 & 14 & 3 \\
OT-112 & $a b c$ & 0 & 1 & 2 & 18 & 4 \\
OT-135 & $a b c$ & 0 & 11 & 3 & 11 & 0 \\
OT-79 & $a$ & 0 & 2 & 4 & 14 & 2 \\
OT-97 & $a$ & 0 & 2 & 0 & 16 & 7 \\
OT-114 & $a$ & 0 & 0 & 1 & 17 & 7 \\
OT-3 & $b$ & 1 & 4 & 3 & 0 & 16 \\
OT-32 & $b$ & 0 & 4 & 5 & 1 & 15 \\
OT-103 & $b$ & 0 & 1 & 4 & 7 & 13 \\
OT-105 & $b$ & 0 & 1 & 7 & 5 & 17 \\
OT-37 & No & 0 & 0 & 0 & 3 & 22 \\
OT-104 & No & 0 & 0 & 0 & 5 & 20 \\
OT-136 & No & 0 & 0 & 0 & 1 & 24
\end{tabular}

${ }^{y}$ Pc58 gene postulations based on previous work by Hoffman et al. (12).

${ }^{\mathrm{z}}$ Crown rust infection types (ITs) were scored on a 0-to-4 scale using the standard scoring system for wheat stem rust IT (30): $0=$ no or very faint hypersensitive flecks, ; = distinct hypersensitive flecks, $1=$ small uredinia surrounded by distinct necrosis, $2=$ small uredinia surrounded by distinct chlorosis, $3=$ moderate sized with or without chlorosis, and $4=$ large uredinia without chlorosis or necrosis.
Barley yellow mosaic virus (16), rice brown planthopper (13), and root-knot nematode in sugarbeet (33). In addition to the markers on OT-2, the AFLP marker e35m61-050.t on OT-8 was associated with reducing DLA and IT in more than one experiment (online $e$ Xtra). This result is consistent with the detection of a QTL on OT8 associated with TAM O-301 alleles characterized by the same AFLP marker linked to reducing uredinial length when inoculated with $P$. coronata pathotype LGCG (15). Additionally, a QTL was detected on LG OT-27 in previous work (15). These same markers were also found to be associated with reducing both DLA and IT in all experiments in this study except 06-Baton Rouge. None of these genetic regions was detected using CIM in this study. One likely explanation for this result was the large effects of the QTL detected on OT-32, which made the detection of minor QTL difficult. Results from the present study and from previous studies show that genetic regions on OT-2, OT-8, and OT-27 would be useful in reducing crown rust infection. Currently, the OT population is being mapped with diversity arrays technology (DArT) markers. This work should provide a greater density of markers in these important locations for better characterization and development of low-cost markers useful for marker-assisted selection.

QTL-reducing crown rust IT and DLA were associated with major crown rust resistance loci $P c 58 a$ on OT-32 and $P c N Q M G /$ $L C G C$ on OT-11. The QTL on OT-11 for reducing IT was detected in three experiments whereas the QTL for reducing DLA was detected in only the 05-Castroville test. In a previous study, a single dominant locus in TAM O-301 characterized by a bleached fleck phenotype was mapped to the same location. In addition, the genetic area conferring the bleached-fleck IT was also responsible for reducing fungal DNA and uredinial length when inoculated with two $P$. coronata pathotypes, NQMG and LGCG (15). As discussed in a previous study (15), it is likely that OT-11 and Kanota/Ogle157 (KO) KO-4 (33) are homologous and, if this is true, the genetic region could be rich in plant defense loci, including those for crown and stem rust $(3,5,22)$.

The QTL accounting for most of the DLA and IT variation across all experiments was detected on LG OT-32. In mapping $P c 58$, Hoffman et al. (12) identified three loosely linked loci and designated them $P c 58 a, b$, and $c$ based on reactions of the same OT RILs to six different $P$. coronata isolates. Susceptible reactions were not observed on RILs containing Pc58a in their study and it was speculated that a fourth allele tightly linked to Pc58a might exist. Our results, which show that OT RILs containing Pc58a had lower DLA and IT, support the observations of Hoffman et al. (10). In addition, the QTL region identified in the present study also accounted for a large reduction in fungal DNA and uredinial length when the OT mapping population was tested in uniform single-isolate polycyclic tests with two different isolates in Aberdeen ID (15). These results suggest that either Pc58a or a tightly linked QTL in this region is a good target for marker-assisted selection. Furthermore, our seedling screening

TABLE 6. Crown rust reactions of $\mathrm{F}_{2}$ populations from crosses of selected Ogle/TAM O-301 (OT) recombinant inbred lines (RILs) with the susceptible cv. Provena grown under natural disease pressure in Castroville, TX

\begin{tabular}{|c|c|c|c|c|c|c|c|}
\hline \multirow[b]{2}{*}{ Population } & \multicolumn{3}{|c|}{ No. of RILs ${ }^{x}$} & \multirow[b]{2}{*}{$\chi^{2}(3: 1)^{y}$} & \multirow[b]{2}{*}{$P$} & \multirow[b]{2}{*}{$\chi^{2}(9: 3: 4)^{z}$} & \multirow[b]{2}{*}{$P$} \\
\hline & $\mathrm{R}$ & I & $S$ & & & & \\
\hline OT-112/Provena & 65 & 26 & 24 & 1.046 & 0.306 & 1.696 & 0.428 \\
\hline OT-62/Provena & 114 & 42 & 47 & 0.340 & 0.543 & 0.685 & 0.710 \\
\hline OT-14/Provena & 50 & 17 & 25 & 0.232 & 0.630 & 0.296 & 0.863 \\
\hline Total $(\mathrm{df}=4)$ & 293 & 120 & 132 & 2.704 & $\ldots$ & 7.136 & $\ldots$ \\
\hline Pooled $(\mathrm{df}=1,2)$ & $\ldots$ & $\ldots$ & $\ldots$ & 0.177 & 0.674 & 3.836 & 0.147 \\
\hline
\end{tabular}

${ }^{\mathrm{x}} \mathrm{R}=$ resistant reactions of bleached flecks with reduced uredinia, $\mathrm{I}=$ intermediate reactions of bleached flecks with medium sized uredinia, and $\mathrm{S}=$ susceptible reactions of large uredinia without bleached flecks.

y Value: $\chi^{2}$ ratio based on resistant and intermediate to susceptible reactions.

${ }^{z}$ Value: $\chi^{2}$ ratio based on resistant to intermediate to susceptible reactions. 
results using 25 different isolates indicated that the genetic region around Pc58abc conferred resistance to 14 of the 25 isolates tested, whereas completely susceptible reactions were only observed when inoculated with 4 of the 25 isolates. Fewer isolates were completely virulent (IT 4) on lines containing Pc58a compared with $P c 58 b$, and lines with $P c 58 a$ had significantly lower IT and DLA on adult plants in the field tests. This result suggests that the genetic region closely linked to $P c 58 a$ appears to be more important. However, it is significant to point out that seven isolates were completely compatible with two of the three lines (OT-114 and OT-97) containing just Pc58a in our seedling test, while four isolates were completely compatible with lines containing all three loci. In addition, no isolates were completely compatible with TAM O-301 and only one of the five RILs with $P c 58 a b c$ had a similar reaction. Thus, additional loci likely exist that enhance crown rust resistance of Pc58abc Currently, work is ongoing to better map the crown rust resistance on OT-32 by developing simple-sequence repeat and single-nucleotide polymorphism markers linked to the region. As previously discussed, the OT population is being mapped with DArT markers which could enable development of low-cost markers for MAS.
Characterization of $\mathrm{F}_{2}$ populations from crosses between OT RILs containing the major loci Pc58a, Pc58b, Pc58c, and $P c N Q M G / L C G C$ and the minor QTL on OT-27 fit a major gene model when the intermediately and highly resistant phenotypes were combined. Because the intermediate resistant phenotype (IT 2) was observed on TAM O-301, and because $P$. coronata races virulent to the allele $P c N Q M G / L C G C$ were avirulent to the alleles in the Pc58 complex, a locus in the Pc58 complex could account for the expression of the intermediate IT. The fact that the QTL on OT-32 accounted for a majority of the IT variance would also support this conclusion. When the intermediate and highly resistant phenotypes were classified separately, segregation of the $F_{2}$ populations fit a two-additive-gene model. The highly resistant phenotype was not observed in the TAM O-301 parent and the only QTL in Ogle1040 conferring crown rust resistance was on OT-27; therefore, the most probable explanation for the highly resistant phenotype would be additive epitasis effect of $P c 58 a$ and the minor QTL on OT-27.

In summary, the present study has confirmed and further characterized key areas in the oat genome that reduce crown rust infection when challenged with naturally occurring pathogen
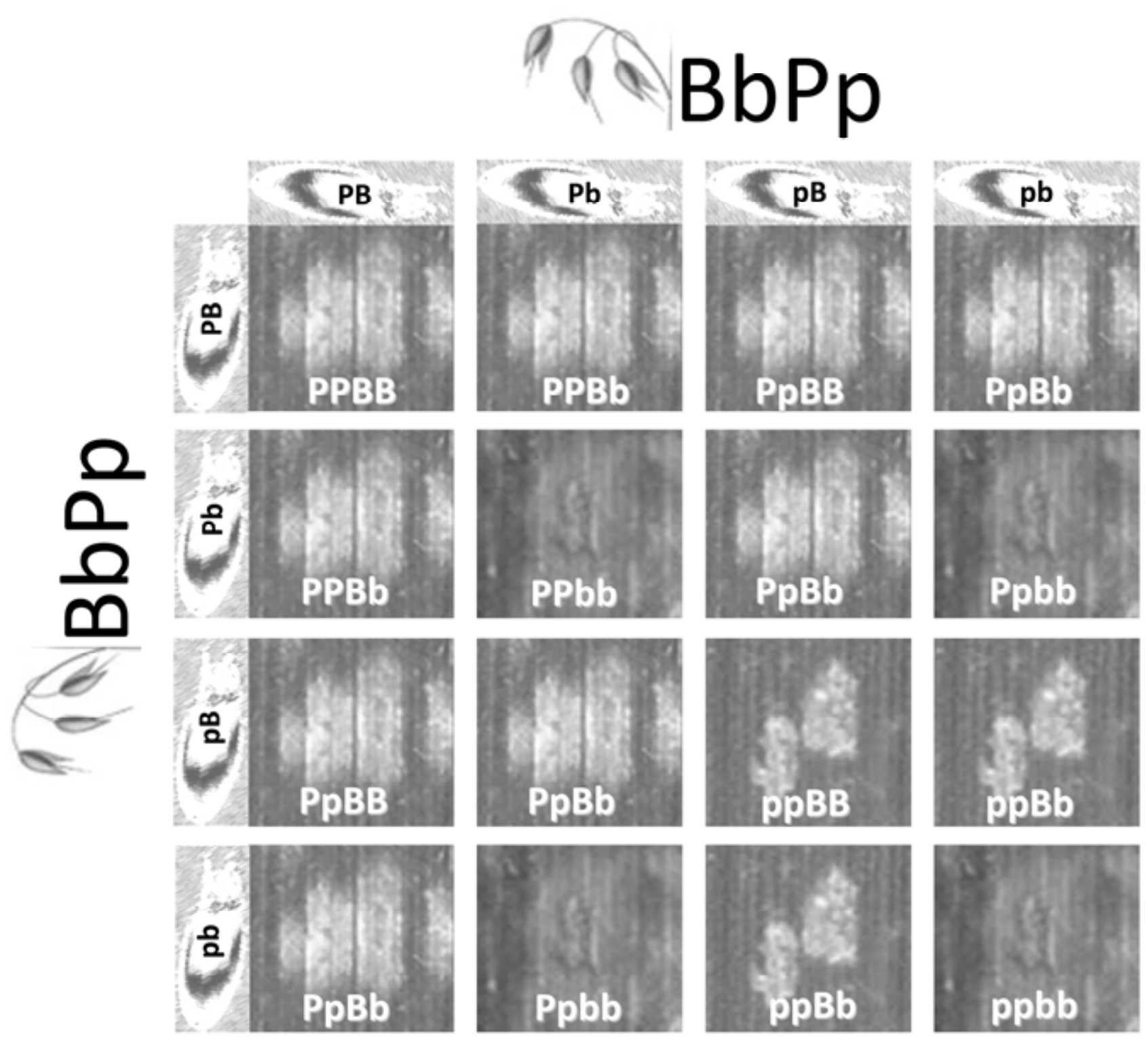

Fig. 4. Segregation model for loci controlling crown rust infection in the Ogle/TAM O-301 RIL population. Presence of one gene on OT-11 (B allele) results in a 3:1 Mendelian ratio for a single gene, resulting in a bleached fleck. Presence of an additional gene on OT-27 (P allele) results in a 9:3:4 genetic ratio, resulting in a bleached fleck with reduced pustules only in the presence of the B allele. 
populations in highly conducive environments. The same QTL associated with reducing crown rust IT and DLA under natural disease pressure in multilocation tests were previously identified in experiments using artificially produced single-isolate adult plant test in Aberdeen, ID $(14,15)$. The potential major advantage to using single-isolate induced epidemics is to eliminate confounding effects of mixed virulent and avirulent reactions in the presence of multiple races. The potential disadvantage to singleisolate testing is the lack of phenotypic information generated by a single isolate, particularly in cases were a single locus confers complete resistance to the isolate. This work, combined with previous reports $(14,15)$, indicates that precise evaluation of using single isolates, even in the case of a locus conferring resistance to the isolate used, can identify the genetic regions, including minor QTL, with higher precision than multilocation field experiments

\section{ACKNOWLEDGMENTS}

We thank R. Harringon, K. Satterfield, I. Shackelford, and R. Caldera for their technical expertise in laboratory and field experiments.

\section{LITERATURE CITED}

1. Arumuganathan, K., and Earle, E. D. 1991. Nuclear DNA content of some important plant species. Plant Mol. Biol. 9:208-219.

2. Barbosa, M. M., Federizzi, L. C., Milach, S. C. K., Martinelli, J. A., and Thome, G. C. 2006. Molecular mapping and identification of QTLs associated to oat crown rust partial resistance. Euphytica 150:257-269.

3. Bush, A. L., and Wise, R. P. 1996. Crown rust resistance loci on linkage groups 4 and 13 in cultivated oat. J. Hered. 87:427-432.

4. Carson, M. L. 2009. Virulence frequencies in oat crown rust in the United States from 2001 through 2005. Plant Dis. 97:379-384.

5. Cheng, D. W., Armstrong, K. C., Tinker, N. A., Wight, C. P., He, S., Anissa, L., Fedak, G., and Molnar, S. J. 2002. Genetic and physical mapping of Lrk 10-like receptor kinase sequences in hexaploid oat (Avena sativa L.). Phytopathology 45:100-109.

6. Chong, J., Gruenke, J., Dueck, R., Mayert, W., and Woods, S. 2008. Virulence of oat crown rust (Puccinia coronata f. sp. avenae) in Canada during 2002-2006. Can. J. Plant Pathol. 30:115-123.

7. Chong, J., and Kolmer, J. A. 1993. Virulence dynamics and phenotypic diversity of Puccinia coronata f. sp. avenae in Canada from 1974 to 1990. Can. J. Bot. 71:248-255.

8. Chong, J., and Zegeye, T. 2004. Physiologic specialization of Puccinia coronata f. sp. avenae, the cause of oat crown rust, in Canada from 1999 to 2001. Can. J. Plant Pathol. 26:97-108.

9. Churchill, G. A., and Doerge, R. W. 1994. Empirical threshold values for quantitative trait mapping. Genetics 138:963-971.

10. Diaz-Lago, J. E., Stuthman, D. D., and Abadie, T. E. 2002. Recurrent selection for partial resistance to crown rust in oat. Crop Sci. 42:14751482 .

11. Gronnerod, S., Maroy, A. G., Mackey, J., Tekauz, A., Penner, G. A., and Bjornstad, A. 2002. Genetic analysis of resistance to barley scald (Rhynchosporium secalis) in the Ethiopian line 'Abyssinian' (CI668). Euphytica 126:235-250.

12. Hoffman, D. L., Chong, J., Jackson, E. W., and Obert, D. E. 2006. Characterization and mapping of a crown rust gene complex (Pc58) in TAM O-301. Crop Sci. 46:2630-2635.

13. Huang, N., Parco, A., Mew, T., Magpantay, G., McCouch, S., Guiderdoni,
E., Xu, J., Subudhi, P., Angeles, E. R., and Khush, G. S. 1997. RFLP mapping of isozymes, RAPD, and QTLs for grain shape, brown planthopper resistance in a doubled haploid rice population. Mol. Breed. 3:105-113

14. Jackson, E. J., Obert, D. E., Menz, M., Hu, G., Avant, J. B., and Bonman, J. M. 2007. Characterization and mapping oat crown rust resistance using three assessment methods. Phytopathology 97:1063-1070

15. Jackson, E. J., Obert, D. E., Menz, M., Hu, G., and Bonman, J. M. 2008. Qualitative and quantitative trait loci conditioning resistance to Puccinia coronata pathotypes NQMG and LGCG in the oat (Avena sativa L.) cultivars Ogle and TAM O-301. Theor. Appl. Genet. 116:517-527.

16. Konishi, T., Ban, T., Iida, Y., and Yoshimi, R. 1997. Genetic analysis of disease resistance to all strains of BaYMV in a Chinese barley landrace, Mokusekko 3. Theor. Appl. Genet. 94:871-877.

17. Leonard, K. J. 2003. Regional frequencies of virulence in oat crown rust in the United States from 1990 through 2000. Plant Dis. 87:1301-1310.

18. Leonard, K. J., Anikster, Y., and Manisterski, J. 2005. Virulence associations in oat crown rust. Phytopathology 95:53-61.

19. Leonard, K. J., Huerta-Espino, J., and Salmeron, J. J. 2005. Virulence of oat crown rust in Mexico. Plant Dis. 89:941-948.

20. Leonard, K. J., and Martinelli, J. A. 2005. Virulence of oat crown rust in Brazil and Uruguay. Plant Dis. 89:802-808.

21. Martens, J. W., and Dyck, P. L. 1989. Genetics of resistance to rust in cereals from a Canadian perspective. Can. J. Plant Pathol. 11:78-85.

22. O’Donoughue, L. S., Chong, J., Wight, C. P., Fedak, G., and Molnar, S. J. 1996. Localization of stem rust resistance genes and associated molecular markers in cultivated oat. Phytopathology 86:719-727.

23. Parlevliet, J. E. 1985. Resistance of the non-race-specific type. Pages 501525 in: The Cereal Rusts, Vol. II. A. P. Roelfs and W. R. Bushnell, eds. Academic Press, New York.

24. Pederson, W. L., and Leath, S. 1988. Pyramiding major genes for resistance to maintain residual effects. Annu. Rev. Phytopathol. 26:369-378.

25. Peterson, R. F., Campbell, A. B., and Hannah, A. E. 1948. A diagrammatic scale for estimating rust intensity on leaves and stems of cereals. Can. J. Res. 26:496-500.

26. Portyanko, V. A., Chen, G., Rines, H. W., Phillips, R. L., Leonard, K. J., Ochocki, G. E., and Stuthman, D. D. 2005. Quantitative trait loci for partial resistance to crown rust, Puccinia coronata, in cultivated oat, Avena sativa L. Theor. Appl. Genet. 111:313-324.

27. Portyanko, V. A., Hoffman, D. L., Lee, M., and Holland, J. B. 2001. A linkage map of hexaploid oat based on grass anchor DNA clones and its relationship to other oat maps. Genome 44:249S-265.

28. Roelfs, A. P., and Martens, J. W. 1988. An international system of nomenclature for Puccinia graminis f. sp. tritici. Phytopathology 78:526-533.

29. Simons, M. D. 1985. Crown rust. Pages 131-172 in: The Cereal Rusts, Volume II. A. P. Roelfs, and W. R. Bushnell, eds. Academic Press, New York.

30. Simons, M. D., Martens, J. W., McKenzie, R. I. H., Nishiyama, I., Sadanaga, K., Sebesta, J., and Thomas, H. 1978. Oats: A standard system of nomenclature for genes and chromosomes and catalog of genes governing characters. U. S. Dep. Agric. Handb. No. 509.

31. Wang, S., Basten, C. J., and Zeng, Z. B. 2005. Windows QTL Cartographer 2.5. Department of Statistics, North Carolina State University, Raleigh.

32. Wight, C. R., Tinker, N. A., Kianian, S. F., Sorrells, M. E., O'Donoughue, L. S., Hoffman, D. L., Groh, S., Scoles, G. J., Li, C. D., Webster, F. H., Phillips, R. L., Rines, H. W., Livingston, S. M., Armstrong, K. C., Fedak, G., and Molnar, S. J. 2003. A molecular marker map in 'Kanota' $\times$ 'Ogle' hexaploid oat (Avena spp.) enhanced by additional markers and a robust framework. Genome 46:28-47.

33. Zeng, Z. 1994. Precision mapping of quantitative trait loci. Genetics 136:1457-1468. 